\title{
The prevalence of subclinical thyroid disease in a sample of pregnant women with hypertension during labor: A cross-sectional study
}

\begin{tabular}{c}
\hline Afan Sulaiman Maghded \\
\hline Abstract
\end{tabular}

Background and objective: Hypertensive disorders during pregnancy remain one of the major causes of maternal and fetal morbidity and death. Subclinical thyroid disease may play an important underlying cause of hypertension during pregnancy. This study aimed to find out the prevalence of subclinical thyroid disease in a sample of pregnant women with hypertension during labor.

Methods: A cross sectional study was performed at the Maternity Teaching Hospital, Erbil city, Kurdistan region, Iraq, from January to December 2016.Two hundred fifty women were included in this study, all with hypertension related to pregnancy (pregnancy induced hypertension, pre-eclampsia, and eclampsia). The TSH and serum free T4 levels were estimated and the participants were classified to be euthyroid, subclinical hyperthyroid, or subclinical hypothyroid. A specially designed questionnaire was used to collect data.

Results: Of the 250 women included in our study, 191 (76.4\%) had TSH levels within the normal range and were considered to be euthyroid, $59(23.4 \%)$ had TSH levels more than 4 milliunits/L meeting the criteria of sub-clinical hypothyroidism. There were no cases of subclinical hyperthyroidism (TSH level below normal).

Conclusion: Subclinical thyroid disease may be a contributory factor in the development of hypertension during pregnancy. No correlation was found between subclinical hyperthyroidism and hypertension during pregnancy.

Keywords: Subclinical thyroid disease; Preeclampsia; Eclampsia; Hypertension; Prevalence.

\section{Introduction}

Subclinical thyroid dysfunction (STD), including subclinical hyperthyroidism and subclinical hypothyroidism, is diagnosed biochemically and defined as an asymptomatic condition with normal levels of free thyroxin (FT4) in the presence of primary abnormalities of serum thyroid stimulating hormone (TSH). Until now, the relationship between STD and blood pressure has been controversial and has not received sufficient attention. Several recent studies showed that subclinical hyperthyroidism had no correlation with hypertension, while some communitybased investigations stated that the relationship between subclinical hypothyroidism and hypertension was very similar to the relationship of overt hypothyroidism and increased blood pressure. ${ }^{1,2}$ Many studies suggesting a possible link with subclinical thyroid dysfunction and pregnancy-associated hypertension, there is further evidence of vascular-related sequelae. Specifically, autoimmune thyroid disorders have been associated with an increased risk for placental abruption. These observations, when coupled with the pathologic cardiovascular effects of overtly abnormal increased or decreased thyroid hormone production, prompted the current study to further investigate the prevalence of subclinical thyroid dysfunction in hypertensive pregnant women. ${ }^{3-6}$ This study aimed to find out the prevalence of

${ }^{1}$ Maternity Teaching Hospital, Erbil, I raq.

* Correspondence: valen8484@yahoo.com 
subclinical hypothyroidism in a sample of pregnant women with hypertension during labor at the Maternity Teaching Hospital in Erbil, Iraqi Kurdistan Region.

\section{Methods}

A cross-sectional study was conducted in the labor room of the Maternity Teaching Hospital in Erbil city from January to December 2016. The proposal to conduct this study was approved byt he Ethics and Scientific Committee of the Kurdistan Board of Medical Specialties. Two hundred fifty women were included in this study. They were admitted to the labor room and diagnosed to have hypertension in pregnancy (pregnancy induced hypertension, pre-eclampsia, and eclampsia), with or without treatment. The cause of admission to the labor room was spontaneous labor, induction of labor, or termination of pregnancy. The inclusion criteria were any woman with systolic BP $>140 \mathrm{mmHg}$ or diastolic BP $>90 \mathrm{mmHg}$ with gestational age between 24-42 weeks, of any age group, with any BMI and of any parity and accepted to participate in the study. Women with overt thyroid disease and chronic hypertension were excluded from the study. Hypertensive disorders of pregnancy were classified into three types. Pregnancy induced hypertension $(\mathrm{PIH})$ is defined as a persistent blood pressure of $140 / 90 \mathrm{mmHg}$ after 20 weeks of gestation. Pre-eclampsia (PE) is hypertensive women who had proteinuria of $1+$ or more determined by urine dipstick analysis from a catheterized sample with blood pressure higher than $160 / 110 \mathrm{mmHg}$. Eclampsia was defined as the onset of seizures (convulsions) in pre-eclamptic women. ${ }^{7}$ Written consent was obtained from all patients after explaining to them the methods and the purpose of the study. A thorough history was taken from the patients to exclude those who were not going with the selected criteria for participation in the study. The data were collected in a special format arranged for this purpose to cover the age of the patient, obstetrical history, past medical history, gestational age (measured by last menstrual period and approved by early pregnancy ultrasound), the type of hypertension. General, abdominal, and vaginal examinations were performed, and vital signs were checked. About $5.0 \mathrm{ml}$ of peripheral blood was drawn from each woman and transferred into a sterile glass tube. Samples were kept in an ice chamber following collection and during transportation to the laboratory. After centrifugation, serum samples were collected in micro centrifuge tubes and stored at- $20^{\circ} \mathrm{Cuntil}$ estimation of $\mathrm{TSH}$ and T4 level. This procedure was done in a privet laboratory clinic, and the results were obtained within 48 hours as a range. Normal ranges used for TSH levels were 0.04 to $4 \mathrm{~m} \mathrm{U} / \mathrm{L}$. Women with serum TSH levels within the normal range were considered to be euthyroid. Those with an abnormally low serum TSH $<0.04 \mathrm{~m} \mathrm{U} / \mathrm{L}$ were classified as having subclinical hyperthyroidism. women with abnormally high TSH levels $>4 \mathrm{~m} \mathrm{U/L}$ were classified as having subclinical hypothyroidism. ${ }^{8,9}$ Data were analyzed using the Statistical Package for Social Sciences (SPSS, version 22). Means and standard deviations were used to summarize the numerical variables. The categorical variables were presented as frequencies and proportions. The Chi-square test of association was used to compare proportions. Fisher's exact test was used when the expected count of more than $20 \%$ of the cells of the table was less than 5. A $P$ value of $\leq 0.05$ was considered as statistically significant.

\section{Results}

Two hundred fifty hypertensive pregnant women participated in the study. Their mean age $( \pm S D)$ was $28.11 \pm 5.96$ years, ranging from 17 to 40 years. The median was 28.5 years. Table 1 shows that around half of them were in the age range 25-34 years, and the majority $(74.8 \%)$ were multi-parous women. 
The prevalence of subclinical thyroid disease .......

Zanco J. Med. Sci., Vol. 23, No. (3), December, 2019 https:/ / doi.org/ 10.15218/ zjms.2019.045

Regarding the gestational age, it was less than 32 weeks in $16 \%$ of the women, 32-35 weeks in $39.2 \%$ of the women, and it was $36-39$ weeks among the

Table 1: Basic characteristics of the study sample.

\begin{tabular}{lcccc}
\hline & No. & $(\%)$ & Mean & $( \pm$ SD) \\
\hline Age (years) & 83 & $(33.2)$ & 28.11 & $( \pm 5.96)$ \\
$<25$ & 127 & $(50.8)$ & & \\
$25-34$ & 40 & $(16.0)$ & & \\
$\geq 35$ & & & & \\
Parity & 50 & $(20.0)$ & 1.87 & \\
Primi-para & 187 & $(74.8)$ & & \\
Multi-para & 13 & $(5.2)$ & & \\
Grand Multi-para & & & & \\
Gestational age (weeks) & 40 & $(16.0)$ & 34.60 & \\
$<32$ & 98 & $(39.2)$ & & \\
$32-35$ & 112 & $(44.8)$ & & \\
$36-39$ & 250 & $(100.0)$ & \\
Total & & & \\
\hline
\end{tabular}

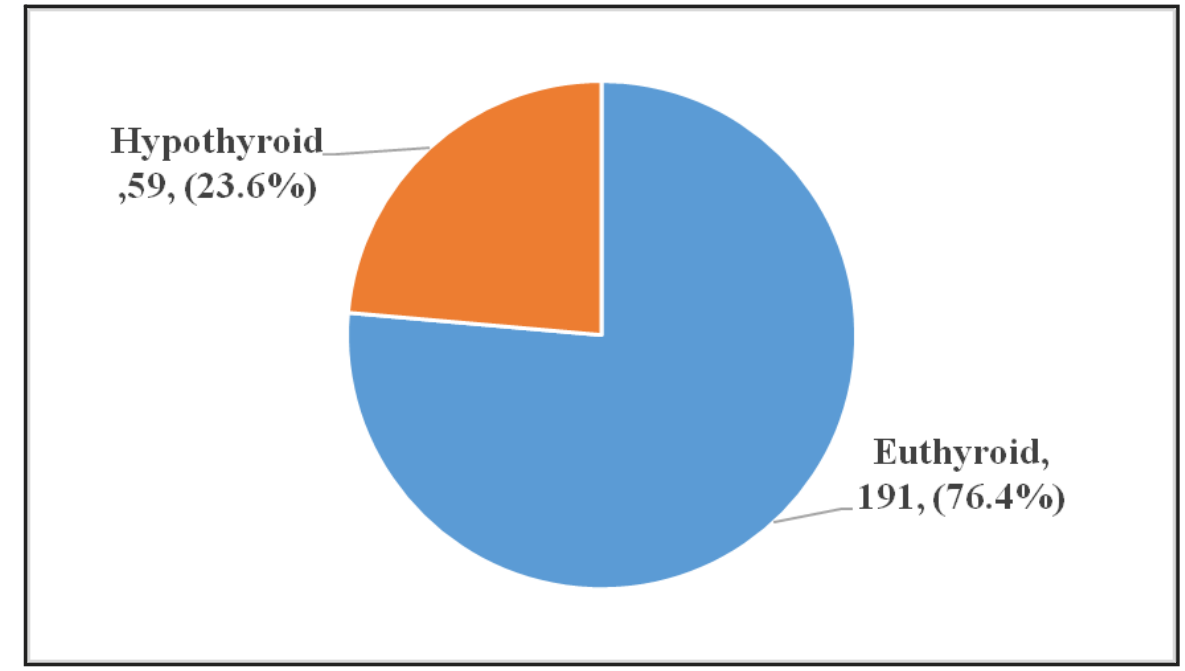

Figure 1: Prevalence of sub-clinical hypothyroidism. 
The prevalence of subclinical thyroid disease .......

Zanco J. Med. Sci., Vol. 23, No. (3), December, 2019 https:/ / doi.org/ 10.15218/ zjms.2019.045

Table 2 shows no significant association between the prevalence of subclinical hypothyroidism with age $(P=0.157)$, parity smoking $(P=0.185)$, multiple pregnancy $(P=0.719)$, gestational age $(P=0.571)$, $(P=0.559)$, and educational level $(P=0.288)$.

Table 2: Prevalence of sub-clinical hypothyroidism by the studied variables.

\begin{tabular}{|c|c|c|c|c|c|c|c|}
\hline & \multicolumn{2}{|c|}{ Euthyroid } & \multicolumn{2}{|c|}{$\begin{array}{c}\text { Subclinical } \\
\text { Hypothyroidism }\end{array}$} & \multicolumn{2}{|c|}{ Total } & \multirow[b]{2}{*}{$P$ value } \\
\hline & No. & (\%) & No. & (\%) & No. & (\%) & \\
\hline \multicolumn{8}{|l|}{ Age } \\
\hline$<25$ & 61 & $(73.5)$ & 22 & $(26.5)$ & 83 & $(100.0)$ & 0.157 \\
\hline $25-34$ & 103 & $(81.1)$ & 24 & (18.9) & 127 & $(100.0)$ & \\
\hline$\geq 35$ & 27 & $(67.5)$ & 13 & $(32.5)$ & 40 & $(100.0)$ & \\
\hline \multicolumn{8}{|l|}{ Parity } \\
\hline Primi & 39 & $(78.0)$ & 11 & $(22.0)$ & 50 & $(100.0)$ & 0.719 \\
\hline Multi & 141 & $(75.4)$ & 46 & $(24.6)$ & 187 & $(100.0)$ & \\
\hline Grand Multi & 11 & $(84.6)$ & 2 & $(15.4)$ & 13 & $(100.0)$ & \\
\hline \multicolumn{8}{|l|}{ GA } \\
\hline$<32$ & 29 & $(72.5)$ & 11 & $(27.5)$ & 40 & $(100.0)$ & 0.571 \\
\hline $32-35$ & 73 & $(74.5)$ & 25 & $(25.5)$ & 98 & $(100.0)$ & \\
\hline $36-39$ & 89 & $(79.5)$ & 23 & $(20.5)$ & 112 & $(100.0)$ & \\
\hline \multicolumn{8}{|l|}{ Smoking } \\
\hline Non-smoker & 176 & $(77.5)$ & 51 & $(22.5)$ & 227 & $(100.0)$ & 0.185 \\
\hline Smoker & 15 & $(65.2)$ & 8 & $(34.8)$ & 23 & $(100.0)$ & \\
\hline \multicolumn{8}{|c|}{ Multiple pregnancy } \\
\hline Single & 179 & $(76.8)$ & 54 & $(23.2)$ & 233 & $(100.0)$ & $0.559^{*}$ \\
\hline Multiple & 12 & $(70.6)$ & 5 & $(29.4)$ & 17 & $(100.0)$ & \\
\hline \multicolumn{8}{|c|}{ Educational level } \\
\hline Illiterate & 14 & $(70.0)$ & 6 & $(30.0)$ & 20 & $(100.0)$ & 0.288 \\
\hline Primary & 90 & $(78.3)$ & 25 & $(21.7)$ & 115 & $(100.0)$ & \\
\hline Secondary & 64 & $(71.9)$ & 25 & $(28.1)$ & 89 & $(100.0)$ & \\
\hline High school & 23 & $(88.5)$ & 3 & $(11.5)$ & 26 & $(100.0)$ & \\
\hline Total & 191 & $(76.4)$ & 59 & $(23.6)$ & 250 & $(100.0)$ & \\
\hline
\end{tabular}

*By Fisher's exact test 
Table 3 shows a significant association between the prevalence of subclinical hypothyroidism and the type of hypertension $(P<0.001)$. The prevalence was $10.8 \%$ among patients with pregnancy induced hypertension, $29.9 \%$ among those with pre-eclampsia, and $47.6 \%$ among patients with eclampsia.

\section{Discussion}

Different factors may play an important role in the development of different types of hypertension during pregnancy. The etiology of hypertensive disorders of pregnancy is clearly unknown, and it may occur at the second or third trimester of pregnancy. Some showed an association between the levels of thyroid hormones and the development of hypertension during pregnancy. ${ }^{10}$ In this study, we found that $23.6 \%$ (59 of 250) had subclinical hypothyroidism (high TSH level), all of them with hypertension despite treatment, with a history of pregnancy induced hypertension, pre-eclampsia, and eclampsia. The remaining patients had a normal TSH level, so regarded as euthyroid. No cases of subclinical hyperthyroidism were found. Some studies have shown that there were no significant differences in TSH levels between pre-eclampsia and healthy women which is different from our results. ${ }^{11}$ Other research found that the increased level of TSH in pre-eclamptic women shows an association with the risk for the development and severity of preeclampsia. ${ }^{12}$ Many studies indicated that pre-eclamptic women showed significantly increased or no significant elevated level of $\mathrm{TSH}$, this alteration may occur as a result of the association of increased level of $\mathrm{TSH}$ with thyroid peroxidase antibodies, $78 \%$ of severely pre-eclamptic women had raised TSH level as compared with only $32 \%$ of women with mild pre-eclampsia. 13 Thyroid dysfunction may change thyroid hormone secretion which can significantly increase T3 and T4 levels in severe pre-eclamptic women. ${ }^{13}$ Thyroid hormone may affect hypertensive disorders onset in pregnant women. An elevated level of thyroid hormones can be the cause of endothelial cell dysfunction, which has an important role in the pathophysiology of hypertensive diseases during pregnancy. ${ }^{14}$ Another study found that subclinical hyperthyroid women who had the lowest $\mathrm{TSH}$ levels had an incidence of hypertensive disorders of $6.2 \%$ compared $8.5 \%$ of euthyroid women and $10.9 \%$ of subclinical hypothyroid women. ${ }^{15}$ The research done by Sahu et al. show results similar to this study, he found that subclinical hypothyroidism among the Indian pregnant women had increased risk of pre-eclampsia in comparison to euthyroid women, $21.8 \%$ of women with

Table 3: Prevalence of sub-clinical hypothyroidism by type of hypertension.

\begin{tabular}{lccccccc}
\hline & \multicolumn{2}{c}{ Euthyroid } & $\begin{array}{c}\text { Subclinical } \\
\text { Hypothyroidism }\end{array}$ & \multicolumn{2}{c}{ Total } & \\
\hline Type of hypertension & No. & $(\%)$ & No. & $(\%)$ & No. & $(\%)$ & $P$ value \\
$\begin{array}{l}\text { Pregnancy induced } \\
\text { hypertension }\end{array}$ & 91 & $(89.2)$ & 11 & $(10.8)$ & 102 & $(100.0)$ & \\
$\begin{array}{l}\text { Pre-eclampsia } \\
\text { Eclampsia }\end{array}$ & 89 & $(70.1)$ & 38 & $(29.9)$ & 127 & $(100.0)$ & $<0.001$ \\
Total & 11 & $(52.4)$ & 10 & $(47.6)$ & 21 & $(100.0)$ & \\
\hline & 191 & $(76.4)$ & 59 & $(23.6)$ & 250 & $(100.0)$ & \\
\hline
\end{tabular}


subclinical hypothyroidism and $41.7 \%$ of women with overt hypothyroidism had pre-eclampsia in the study group in comparison to $8.2 \%$ of euthyroid. ${ }^{16}$ Women who experienced pre-eclampsia might have an increased risk for reduced thyroid functions later in life. ${ }^{17}$

\section{Conclusion}

Subclinical hypothyroidism could be a contributory factor for the development of hypertension during pregnancy as subclinical hypothyroidism were found in patients with hypertensive disorders during pregnancy.

\section{Competing interests}

The authors declare no competing interests.

\section{References}

1. Duan $Y$, Peng $W$, Wang $X$, Tang W, Liu X, $\mathrm{Xu} S$, et al. Community-based study of the association of subclinical thyroid dysfunction with blood pressure. Endocrine 2009; 35:136-42.

2. Garg A, Vanderpump MPJ. Subclinical thyroid disease. Br Med Bull 2013; 107(1):101-16.

3. Abbassi-Ghanavati M, Casey BM, Spong CY, Mclntire DD, Halvorson LM, Cunningham FG. Pregnancy outcomes in women with thyroid peroxidase antibodies. Obstet Gynecol 2010; 116:381-6.

4. Casey BM, Dashe JS, Wells CE, Mclntire DD, Byrd W, Leveno KJ, et al. Subclinical hypothyroidism and pregnancy outcomes. Obstet Gynecol 2005; 105:239-45.

5. Cleary-Goldman J, Malone FD, LambertMesserlian G, Sullivan L, Canick J, et al. Maternal thyroid hypofunction and pregnancy outcome. Obstet Gynecol 2008; 112:85-92.

6. Haddow JE, McClain MR, Palomaki GE, Neveux LM, Lambert-Messerlian G, et al. Thyroperoxidase and thyroglobulin antibodies in early pregnancy and placentalabruption. Obstet Gynecol 2011; 117(2 Pt 1):287-92.

7. National Institute for Health and Clinical Excellence. Hypertension in pregnancy. NICE Clinical Guidelines 107; 2010. (Accessed January 12, 2017, at; www.nice.org.uk/nicemedia/ live/13098/50418/50418.pdf).

8. Cooper DS, Biondi B. Subclinical thyroid disease. The Lancet 2012; 379(9821):1142-54.

9. BTA A, BTF $U$. Guidelines for the use of thyroid function tests. Association for Clinical Biochemistry, British Thyroid Association. British Thyroid Foundation, Londres; 2006.
10. Hasanzadeh $M$, Ayatollahi $H$, Farzadnia $M$, Ayati S, Khoob MK. Elevated plasma total homocysteine in preeclampsia. Saudi Med J 2008; 29(6):875-8.

11. Qublan HS, Al-Kaisi IJ, Hindawi IM, Hiasat MS, Awamleh I, Hamaideh $\mathrm{AH}$, et al. Severe pre-eclampsia and maternal thyroid function. J Obstet Gynaecol 2003; 23:244-6.

12. Mostaghel N, Tavanayanfar E, NeisaniSamani E. Association of maternal hypothyroidism with pre-eclampsia. Iranian Journal of Pathology 2008; 3(2):51-4.

13. Sardana D, Nanda S, Kharb S. Thyroid hormones in pregnancy and preeclampsia. J Turk German Gynaecol Assoc 2009; 10:168-71.

14. Steegers EA, von Dadelszen P, Duvekot JJ, Pijnenborg R. Pre-eclampsia. Lancet 2010; 376:631-44.

15. Wilson KL, Casey BM, Mclntire DD, Halvorson LM, Cunningham FG. Subclinical thyroid disease and the incidence of hypertension in pregnancy. Am J Obstet Gynecol 2012; 119(2):315-20.

16. Sahu MT, Das V, Mittal S, Agarwal A, Sahu M. Overt and subclinical thyroid dysfunction among Indian pregnant women and its effect on maternal and fetal outcome. Arch Gynecol Obstet 2010; 281(2):215.

17. Lavine RJ, Lindheimer MD. First trimester prediction of early preeclampsia: A possibility at last. Hypertension 2009; 53:747-8. 